\title{
The Critical Challenge of Educating the Public About Genetics
}

\author{
Michael J. Dougherty • Katherine S. Lontok • \\ Katherine Donigan $\cdot$ Joseph D. McInerney
}

Published online: 5 April 2014

(c) Springer Science + Business Media New York 2014

\begin{abstract}
The translation of genomics into medicine would benefit from a public that has a strong foundation in core genetics principles and that is able to access, identify, and use reliable information. Unfortunately, public understanding of genetics is generally poor, a condition that can be traced to deficiencies in formal science education, weaknesses in representations of genetics in the media and on the Internet, and the limited knowledge and involvement of health care providers in patient education. Notwithstanding these challenges, the Internet, media, and health professionals likely will remain major sources of public education. Whether those sources contribute positively or negatively will depend, in part, on the public's ability to discriminate high-quality from low-quality information and on health providers' understanding of genetics and their willingness to engage in the genetics education of their patients.
\end{abstract}

Keywords Genomic/genetic literacy $\cdot \mathrm{K}-12$ education · Media $\cdot$ Internet $\cdot$ Health professionals $\cdot$ Public education

M. J. Dougherty $(\bowtie) \cdot$ K. S. Lontok · K. Donigan .

J. D. McInerney

American Society of Human Genetics, 9650 Rockville Pike,

Bethesda, MD 20814, USA

e-mail: mdougherty@ashg.org

K. S. Lontok

e-mail: klontok@ashg.org

K. Donigan

e-mail: kdonigan@ashg.org

J. D. McInerney

e-mail: jmcinerney@ashg.org

M. J. Dougherty

Department of Pediatrics, University of Colorado School of Medicine, Aurora, CO, USA

\section{Introduction}

Genomic medicine is much in the news, from direct-toconsumer genetic testing to the use of cell-free DNA for prenatal diagnosis, and as the complexity and clinical implications of the technology increase, so does the importance of producing a well-educated adult public capable of thoughtful use of those interventions. The evolution of genetic medicine itself requires a careful rethinking of our approaches to public education to ensure that its content reflects the actual nature of our understanding of genetics and its relationship to health and disease.

The content of modern genetics education as it relates to health care is still conditioned - and constrained - to some extent by history. As Childs has explained, and as Fig. 1 illustrates, genetics found its way into medicine through the inborn errors of metabolism, whose natural home was pediatrics [1]. That focus on Mendelian disorders set a conceptual approach to the discipline that served it well, but that also impeded appreciation of the relevance of genetics to other areas of medicine. The recent explosion of genomic data and their relevance to the major causes of morbidity and mortality worldwide, however, require the integration of genetics into all medical specialties.

Because genomics is now finding explanatory power in common, complex disease, we must prepare the public to participate in a health care paradigm that acknowledges the multifaceted interactions of genetic and environmental variables in the onset and expression of disease and in prevention and treatment. For example, the College of American Pathologists recently developed guidelines for the use of pharmacogenetic testing to improve the treatment of certain breast cancers. Herceptin and related drugs that target the human epidermal growth factor receptor 2 (HER2) improve 
Fig. 1 An overview of the integration of genetics into medicine. The American College of Medical Genetics was founded in 1991 (developed by Childs B, Valle D,

McInerney J 2010)

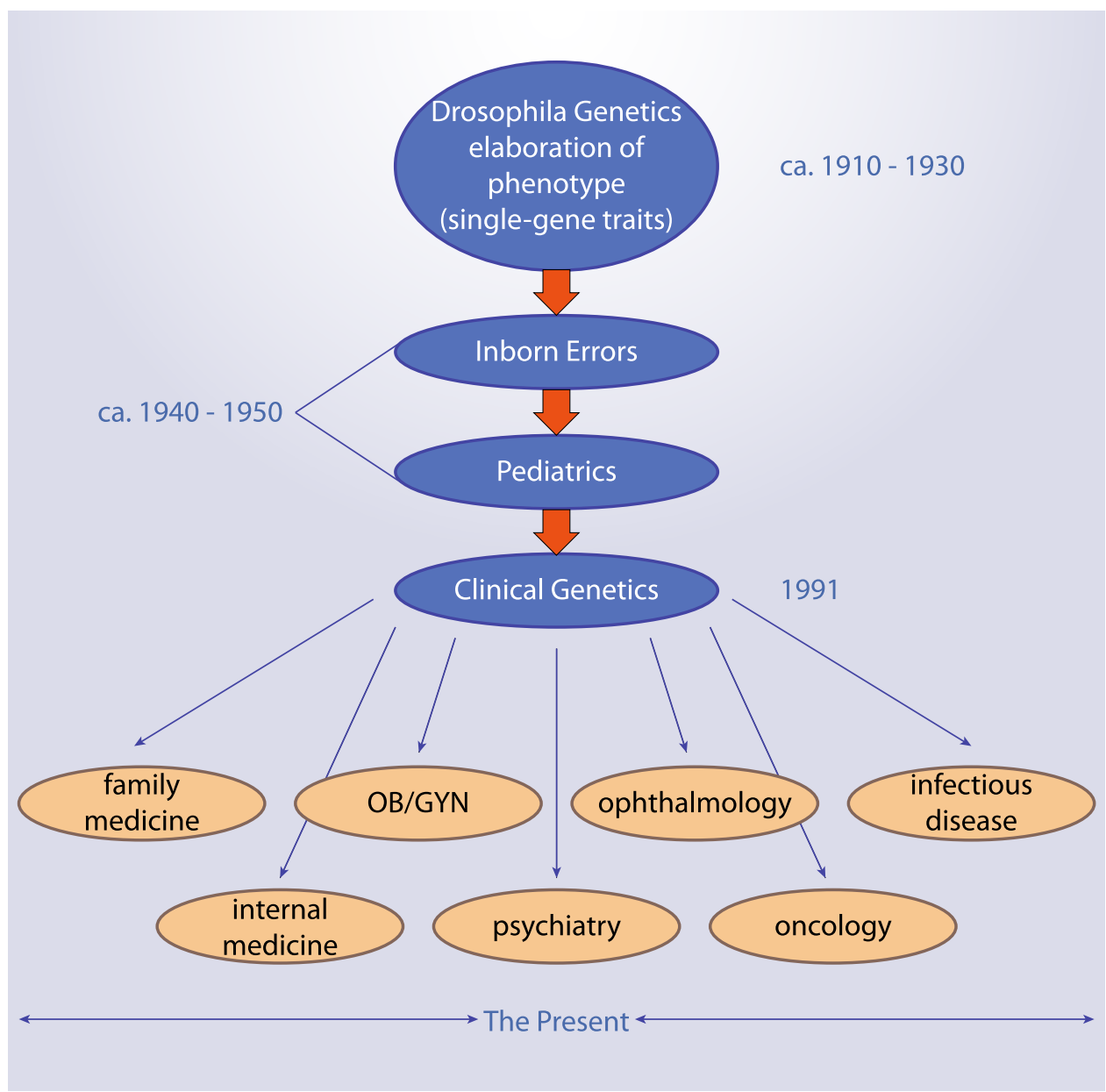

survival in cases of HER2-positive invasive breast cancer, and avoiding its use in HER2-negative patients, for whom those drugs will be ineffective, minimizes adverse events and saves time and money [2]. In another example, patients requiring the blood thinners warfarin or clopidogrel often face complications due to variations in sensitivity to the drugs, which we now know are often related to genetic variation in the CYP2C9 and VKORC1 genes. The American College of Medical Genetics and Genomics has developed recommendations for the use of pharmacogenetic testing for those genes [3], and a number of FDA-cleared tests are being marketed, even though the FDA does not require testing as part of its labeling requirements for those drugs. Wide-scale adoption of genetic tests to improve dosing for many drugs should await the results of large, randomized controlled trials [4], but the trend toward medicine informed by genetics is clear. This new view of genetics requires new approaches to genetics education for the public, approaches that go beyond the traditional concentration on single-gene characters and Mendelian principles.

Adoption of genetic tests in clinical care also will require health insurers to develop coverage and reimbursement policies for these tests. Medicare, being a large-scale health insurance provider, develops standards for coverage and reimbursement that often are adopted by private insurers and state Medicaid programs. Previously, the Medicare billing system focused on general laboratory procedures used to generate test results (e.g., DNA isolation, PCR) rather than a specific genetic test. In 2012, the Centers for Medicare and Medicaid Services (CMS) developed gene-specific codes for approximately 100 genetic tests to be used by Medicare Authorized Contractors (CMS, Recurring Update Notification, Pub. No. 100-04, Transmittal 2365, Change Request 7654, dated 9 December 2011). This new system provides increased transparency in CMS coverage decisions for genetic tests, which will likely influence other insurers. The time needed to gather more evidence, develop decisionsupport tools, and further integrate genetic testing into insurance and health care systems is time that can be used profitably to ramp up educational efforts.

Reasonable lists of concepts defining genetic/genomic literacy, or, in the case of health professionals, "competencies," have been developed for numerous audiences, ranging from high school students to undergraduates to 
physicians and allied health professionals $[5 \bullet, 6,7,8 \bullet, 9 \bullet$, $10,11 \bullet$. Thus, establishing consensus on the important ideas around which educational programs should be developed is not a limiting factor in educating the public or health provider community. Notwithstanding that any list of essential content in a rapidly developing field is necessarily a moving target that will require periodic revision, the greater problem is that even well-established and longstanding genetic principles have not been assimilated into general public knowledge or integrated into medical training and practice. In this article, we will review some of the major deficits in understandings and the reasons that these gaps persist.

\section{Objectives for Public Genetic Literacy}

One of us (JDM) has suggested two central objectives for the promotion of genetic literacy among the public_-adult or otherwise: (1) to foster an understanding of the history and nature of life on earth, including the history and structure of the human population, and (2) to prepare the public for a future where genetics will inform virtually all aspects of health and disease and where we will move toward a prevention-based paradigm that will require full partnership from an informed public [12].

Uncertainty is a central feature of medicine in general, and it is perhaps a bit counterintuitive for the public to understand that more genomic data will increase that uncertainty in the short term rather than decrease it. Complexity and uncertainty will be guiding principles in genomic medicine, and providers and the public must know how to deal with them-conceptually and practically, as when making decisions about treatment and management. Complexity and uncertainty will compound the already well-documented challenges related to the public's understanding of risk $[13,14]$.

Among the general messages that should be inherent in genetics education for the public are the following:

- "genes are not there to cause disease" [15];

- there is a difference between genes and variants, i.e., all of us have the same 20,000 genes, but we all have different variants of those genes;

- some diseases aggregate in certain populations and ethnic groups. We know the reasons for that aggregation in some instances, but not many, and the explanations are rooted in evolution theory; and

- disease itself is a function of the genetic variation necessary for the survival of the species; some of that variation will be disadaptive in some environments, resulting is what we know as disease [1].

\section{Limited Baseline Knowledge of the Lay Public}

Research clearly indicates that problems with genetic literacy are pervasive in adults. Adults generally understand genetics in the context of heredity, but have less knowledge about gene structure, cellular location, and function [16, 17]. They also generally believe that health conditions are influenced by both genes and other factors, but do not express specific understanding of the gene-environment interaction [13, 17]. For example, the public resists the notion that genes might be identified that influence conditions they associate with the environment, and they consider genes as acting separately from the environment $[18 \bullet \cdot, 19]$.

Literacy levels also tend to be lower among older adults [20]. As genomics moves into medicine, this may be particularly problematic because older patients are the most likely to be affected by common complex diseases, such as cancer and heart disease, and the impact of pharmacogenetics. Our understanding of the genetic architecture of complex disease has benefitted tremendously from advances in genotyping and sequencing technology, and many health care organizations, such as pharmaceutical companies and hospital systems, are eager to exploit new research findings for competitive advantage. Other factors that affect adult genetic literacy include extent of formal education, which correlates positively with understanding, and, in some studies, membership in underrepresented racial and/or ethnic groups, which correlates negatively [21, 22•]. If the latter differences are real, the problem of disparity in health care delivery and health outcomes, which already challenges underserved communities, will grow to encompass genomic medicine.

Studies that deal with public understanding in the specific context of genetic testing suggest further reasons for concern. Kaphingst et al. [22•] found that people holding deterministic interpretations of genetic test results, or the belief that traits and diseases are primarily genetically determined, are likely to have lower education levels and to be confused about genetics concepts. Customers of directto-consumer (DTC) genetic tests tend to have low knowledge, but their intention to purchase a DTC test is driven by how much they think they know [23]. Furthermore, a large majority of DTC test customers said they would share their results with their physicians, but fewer than one-third actually did [24]. O'Rourke also found that about one-third of users equated their DTC test results with a diagnosis and raised the possibility that unrealistic expectations by the public could harm genomic medicine [24].

There is reason to believe that DTC testing companies take education seriously because their business model depends, in large part, on consumers deriving value from the information they offer (e.g., test results, interpretations, 
explanations). Production of high-quality educational materials, however, requires more than good intentions. In a study of 29 DTC genetic test company websites, Lachance et al. [25•] found that the educational quality of the information offered varied widely and that many users struggled to find and understand important information, in part because of a reading level that was too high. By providing genetic test results without high-quality educational materials, DTC companies risk misinterpretation of results by consumers, an outcome that is particularly troubling if the consumer uses the results to self-manage a health-related condition.

The potential for harm to consumers prompted the FDA to issue a warning letter to the DTC company 23andMe in November 2013 [26]. The FDA charged that 23andMe was marketing tests without clearance or approval and that further sales had to be discontinued until approval was obtained, citing concerns about test accuracy as well as the release of genetic test results to consumers without the appropriate medical guidance. Shortly after receiving the warning letter, 23andMe stopped offering new customers access to their DTC tests and indicated the company will pursue regulatory approval from the FDA. It is not known whether the rush to market DTC genetic tests to consumers (and subsequent suspension of 23andMe's DTC test) might have a negative impact on the public's trust and views of genetic testing.

The privacy of genetic information, and the public's understanding of current privacy protections, also may influence public acceptance of genetic testing in medicine. The Genetic Information Nondiscrimination Act (GINA), which protects against discrimination in health insurance and employment on the basis of genetic information, illustrates the need to include a policy dimension in genetics education and our goals for genetic literacy. Since GINA's passage in 2008, three cases of genetic discrimination in the workplace have resulted in lawsuits filed by the Equal Employment Opportunity Commission. All cases have involved pre-employment medical exams that included questions about family medical history, which is considered genetic information under GINA. The first lawsuit was settled in the US District Court for the Northern District of Oklahoma (Civil Case No.: 13-CV248-CVE-PJC), and the other cases are pending.

The public has a limited understanding of GINA and the protections it provides. In a study of individuals contacting a disease-advocacy group, approximately $20 \%$ eschewed genetic testing because of concerns about health insurance discrimination [27]. When first considering genetic testing, more than half of study participants expressed concerns over health insurance and nearly a third also worried about impacts on employment. Perhaps more troubling, in a study of family physicians' understanding of GINA conducted nearly a year and a half after the law's passage, approximately half were unaware of the law's existence [28]. This finding suggests that many physicians will be ineffective as advocates for genetic testing with patients who express reservations because of fears of discrimination.

\section{Influence of Formal K-12 Education on Literacy Levels}

Much of what the public understands about genetics comes from the last biology course most people have taken, which, generally speaking, was in 10th grade, and from the media and Internet. At the high school level, misconceptions about meiosis and basic inheritance patterns are common, and gold-standard national exams (e.g., the National Assessment of Educational Progress) reveal poor understanding of basic concepts such as genes and mutations [29, 30]. State science standards, which govern what will be assessed (and thus taught), have been found inadequate with respect to genetics in $85 \%$ of states [5•].

Particularly lacking in the high school curriculum is attention to concepts reflecting the expansion of our understanding of genetics as it has become genomic in scope, for example, differential gene expression, the difference between somatic and germline disease, and the contributions of multiple genes (and the environment) to phenotypes (i.e., polygeny, multifactorial inheritance). The curriculum also fails to address the nature and methods of science adequately, which leaves students ill prepared to answer questions such as "what constitutes sound evidence?" This may leave the public susceptible to information of questionable merit. Alternative approaches to the genetics curriculum have been proposed to help rectify some of these deficiencies, but research is needed to determine the efficacy of those approaches [31, 32].

Regardless of the changes experts recommend, textbook publishers tend to be conservative and will be slow to adopt broad changes, in part because of the outsized impact of "textbook-adoption states," especially large ones such as Texas and Florida. To ensure adoption of their textbooks by state boards of education, which are often elected and highly political entities, publishers take a conservative approach that avoids the inclusion of content perceived by some, often small vocal minorities, as controversial or unfamiliar. This situation works against substantive change in any subject, including biology and genetics. Compounding the curriculum problem is that fact that not all biology teachers are well qualified to teach genetics. Fortysix percent of high school biology teachers do not have a degree in biology, and $26 \%$ have never taken a college genetics course [33]. 


\section{Influence of the Media as a Common Source of Information}

The mass media is a significant source of information for the general public. As a consequence, experts frequently express concern about the health and science information conveyed through media sources. In terms of genetics in the media, one of the most recurrent concerns is promotion of genetic determinism [34]. Not all analyses, however, have supported this concern [35, 36], and some researchers have suggested that genetic determinism in the news media actually may be decreasing over time [37]. What is found more consistently, particularly in stories on the medical and forensic applications of genetics, is overstatement of the potential of genetic technology that may lead to unrealistic public expectations (termed "genetic optimism" by Conrad) [38-40].

Analyses of recent media coverage of Angelina Jolie's decision to undergo double mastectomy as a result of a positive BRCA 1/2 test highlight another common problem: oversimplification. Kamenova et al. [41] found that many stories on Ms. Jolie's decision were missing key information about how rare BRCA $1 / 2$ variants are in the general public. As a result, even members of the public who could accurately recall Ms. Jolie's breast cancer risk could not contextualize that information to an average woman's risk of developing breast cancer [42].

Unfortunately, some of the inaccuracies found in news media can be traced to research press releases and geneticists themselves. Although press releases tend to reflect primary research papers more accurately than do news stories, even claims sourced from institutional press releases have a wide range of accuracy [43••]. In addition, Brechman and Lee found that, in general, news stories increased in accuracy when reporters consulted outside experts but not when they consulted study authors alone. These results indicate that at least some oversimplification and genetic optimism may be due to the desires of researchers and their institutions to promote the significance of their studies to the general public.

\section{Influence of the Internet as a Common Source of Information}

In the most recent Pew Health Online survey, $72 \%$ of Internet users (59\% of the general US adult population) reported accessing online health information, with the large majority turning to search engines such as Google rather than specialty sites such as WebMD [44]. Studies of health information available online, including information on genetic conditions, indicate a wide range of information quality [45-47].
One implication of starting with a search engine rather than a reputable medical site is that users have a higher probability of encountering popular information that is non-relevant or misleading. As a result, this usage pattern actually requires more sophisticated information-filtering skills on the part of the user. Studies show that features such as references to peer-reviewed articles, a top-level domain of .gov or .org, and lack of advertisements can indicate high-quality information [47]. Sites with those features, however, are widely dispersed, and the public uses both relevant indicators, for example, the appearance of the same information on multiple sites, as well as inappropriate indicators, such as site layout, to determine the credibility of presented information [48, 49]. As a partial corrective to this situation, Genetic Alliance and several partners created "Trust It or Trash It?" to help the public and health professionals evaluate the credibility of genetic information on the Web or elsewhere (http://www. ncbi.nlm.nih.gov/books/NBK115530/) [50••].

In addition to assessing the quality of information likely to be encountered, it is important to consider why the public uses the Internet for health information. Medical-genetics patients and parents of children with suspected genetic conditions report using the Internet to self-diagnose, to find specialists, and to increase their genetic literacy or acquire medical vocabulary [51-53]. In fact, patients may rely more heavily on the Internet as a source of genetics information than they do on health professionals [54]. Genetics patients report dissatisfaction with the information provided by health professionals as one of their motivations for accessing online information $[52,55,56]$. That dissatisfaction may be related to the well-documented gaps in health professionals' own understanding of genetics [9, 57]. In addition, a patient's desire to understand a suspected genetic condition as a way of coping [52] may run counter to the techniques medical professionals use to dispense information. A study by Wittmann et al. [58] found that $79 \%$ of patients wanted as much information as possible about their diagnosis, whereas only $35 \%$ of physicians were willing to provide all of the information at their disposal.

Overall, about half of Internet users looking for medical diagnoses share the information they find with a health care provider [44]. Given the reality of heavy patient use of the Internet and the variability in online information quality, clinicians should encourage their patients to share information found online and should point patients toward reputable sources whenever possible. Indeed, many genetics patients feel that clinicians have a duty to provide them with reputable online sources of information [51, 56]. 


\section{Implications of Low Public Literacy for Health Care Providers}

The inevitable integration of genomics into mainstream health care will require a professional community that can initiate relevant conversations with patients and respond knowledgably to their queries. Although the practice of genetic medicine continues to evolve, it is likely that genetics professionals will continue to handle those disorders where the heritability approaches 1 , e.g., metabolic disorders and chromosomal anomalies, whereas nongeneticists will continue to handle those disorders where the heritability is largely less than 1, e.g., cardiovascular disease, diabetes, and mental illness. Those providers, however, will have to bring an understanding of genetics/ genomics content to their diagnoses, clinical judgment, and patient management as continued research identifies salient genetic variants. Their genetic literacy must improve in concert with that of the public they serve if the field is to achieve its promise in personal and public health.

\section{Conclusions}

The improvement of public genetic literacy is an educational challenge that necessarily must address several levels of education and communication. Modernizing genetics education in public K-12 schools is an essential goal, but one challenged by a long time horizon, the complications (in the US) of local control over curriculum, and the baleful impact of uneven teacher quality. These significant barriers emphasize the importance of alternatives to formal K-12 education that may be more effective at promoting the integration of genomics into health care, especially in the near term. The media represent one such alternative, but present their own challenges, including representations of genetics such as genetic optimism and oversimplification of complex topics, which are due to a variety of issues stemming from both journalistic practices and failures in science communication. In communicating with the media, geneticists and their institutions must strive to clearly and accurately communicate complex information and resist the temptation to promise too much of genetics. Providing journalists with the names of third-party experts and encouraging media training for lead authors may reduce the inaccuracies conveyed to journalists and improve the balance and context of media coverage of genetics. The Internet is an almost ubiquitous tool for informing the public, and many sites provide reliable information about basic genetics, genetic tests, and applications of genomics to medicine. Such sites, however, are widely dispersed, and much of the public lacks the skill to discriminate effectively between sound and unsound information.
Information about genetics has never been more accessible, but much of it is oversimplified, overhyped, and misunderstood. Health care providers can help patients make sense of this confusion by presenting genetic information in a clinical context that is relevant to their patients. That clinical skill, however, will require that providers are willing to engage their patients in an early and open dialogue about genetics and that the providers themselves are confident in their own understanding of the field. Success does not require that providers be encyclopedic in their knowledge. Rather, by serving as arbiters of information quality, translators of complexity, and advocates for their patients, health care providers can assist their patients in educating themselves.

Acknowledgments K Donigan is supported by the ASHG Genetics and Public Policy Fellowship.

Disclosure M.J. Dougherty declares no conflicts of interest. K.S. Lontok declares no conflicts of interest. K. Donigan declares no conflicts of interest. J.D. McInerney declares no conflicts of interest.

Human and Animal Rights and Informed Consent All studies by M.J. Dougherty and J.D. McInerney involving animal and/or human subjects were performed after approval by the appropriate institutional review boards. When required, written informed consent was obtained from all participants.

\section{References}

Papers of particular interest, published recently, have been highlighted as:

- Of importance

•- Of major importance

1. Childs B. Genetic medicine: a logic of disease. Baltimore: Johns Hopkins University Press; 1999.

2. American Society of Clinical Oncology - College of American Pathologists Clinical Practice Guideline Update. Recommendations for Human epidermal growth factor 2 testing in breast cancer. College of American Pathologists. 2013. http://www.cap.org/apps/ cap.portaL?_nfpb=true\&cntvwrPtlt_actionOverride $=\% 2$ Fportlets $\% 2$ FcontentViewer\%2Fshow\&_windowLabel=cntvwrPtlt\&cntv wrPtlt $\{$ actionForm.contentReference $\}=$ committees $\% 2$ Fimmuno histochemistry\%2Fher2_index.html\&_state=maximized\&_page Label=cntvwr. Accessed 21 Jan 2014.

3. Flockhart DA, O'Kane D, Williams MS, Watson MS, Flockhart DA, Gage B, et al. Pharmacogenetic testing of CYP2C9 and VKORC1 alleles for warfarin. Genet Med. 2008;10:139-50.

4. Rouse M, Cristiani C, Teng KA. Q: should we use pharmacogenetic testing when prescribing warfarin? Clevel Clin J Med. 2013;80:483-6.

5. - Dougherty MJ, Pleasants C, Solow L, Wong A, Zhang H. A comprehensive analysis of high school genetics standards: are states keeping pace with modern genetics? CBE Life Sci Educ. 2011;10:318-27. This reference describes the results of an 
analysis of state science standards and demonstrates that genetics coverage in those standards is woefully inadequate.

6. Hott AM, Huether CA, McInerney JD, Christianson C, Fowler R, Bender $\mathrm{H}$, et al. Genetics content in introductory biology courses for non-science majors: theory and practice. Bioscience. 2002;52:1024.

7. Kaye C, Korf B. Genetic literacy and competency. Pediatrics. 2013;132:S224-30.

8. - McElhinny TL, Dougherty MJ, Bowling BV, Libarkin JC. The status of genetics curriculum in higher education in the United States: goals and assessment. Sci Educ. 2012;23:1-20. This reference demonstrates incongruence between the genetic literacy goals claimed by university instructors and the goals actually advanced by their curriculum and teaching choices.

9. •- McInerney J, Edelman E, Nissen T, Reed E, Scott J. Perspectives: preparing health professionals for individualized medicine. Pers Med. 2012;9:529-37. This article describes the efforts made by the National Coalition for Health Professional Education in Genetics to develop educational materials to help promote the integration of genomics into medicine.

10. NCHPEG - National Coalition for Health Professional Education in Genetics. Core competencies for all health professionals. NCHPEG. 2007. http://www.nchpeg.org/index.php?option=com content $\&$ view $=$ article $\& i d=237 \&$ Itemid $=84$. Accessed 22 Jan 2014.

11. - Saul RA. Genetic and genomic literacy in pediatric primary care. Pediatrics. 2013;132:S198-202. This reference summarizes a series of articles that emerged from a colloquium on genetic literacy in pediatric primary care.

12. McInerney J. Education in a genomic world. J Med Philos. 2002;27:369-90.

13. Lea DH, Kaphingst KA, Bowen D, Lipkus I, Hadley DW. Communicating genetic and genomic information: health literacy and numeracy considerations. Public Health Genomics. 2011;14:279-89.

14. Vassy JL, O'Brien KE, Waxler JL, Park ER, Delahanty LM, Florez JC, et al. Impact of literacy and numeracy on motivation for behavior change after diabetes genetic risk testing. Med Decis Mak. 2012;32:606-15.

15. Ridley M. Genome: the autobiography of a species in 23 chapters. New York: Harper Perennial; 2006.

16. Christensen KD, Jayaratne TE, Roberts JS, Kardia SLR, Petty EM. Understandings of basic genetics in the United States: results from a national survey of black and white men and women. Public Health Genomics. 2010;13:467-76.

17. Condit C. Public understandings of genetics and health. Clin Genet. 2010;77:1-9.

18. •• Condit CM, Shen L. Public understanding of risks from geneenvironment interaction in common diseases: implications for public communications. public health genomics. 2011;14: 115-24. This study describes the public's complex views on how genes and environment interact to affect risk, disease, and health, with a special focus on the challenges that multifactorial traits will pose for teaching and communication.

19. Morris J, Gwinn M, Clyne M, Khoury MJ. Public knowledge regarding the role of genetic susceptibility to environmentally induced health conditions. Community Genet. 2003;6:22-8.

20. Ashida S, Goodman M, Pandya C, Koehly LM, Lachance C, Stafford J, et al. Age differences in genetic knowledge, health literacy and causal beliefs for health conditions. Public Health Genomics. 2011;14:307-16.

21. Haga SB, Barry WT, Mills R, Ginsburg GS, Svetkey L, Sullivan $\mathrm{J}$, et al. Public knowledge of and attitudes toward genetics and genetic testing. Genet Test Mol Biomark. 2013;17:327-35.

22. - Kaphingst KA, McBride CM, Wade C, Alford SH, Reid R, Larson E, et al. Patients' understanding of and responses to multiplex genetic susceptibility test results. Genet Med.
2012;14:681-7. This reference describes a study of patients' responses to direct-to-consumer genetic test results and certain relationships between participants' answers to survey questions and their demographic characteristics.

23. Pearson YE, Liu-Thompkins Y. Consuming direct-to-consumer genetic tests: the role of genetic literacy and knowledge calibration. J Public Policy Mark. 2012;31:42-57.

24. O'Rourke PP. Genomic medicine: too great expectations? Clin Pharmacol Ther. 2013;94:188-90.

25. - Lachance CR, Erby LAH, Ford BM, Allen VC, Kaphingst KA. Informational content, literacy demands, and usability of websites offering health-related genetic tests directly to consumers. Genet Med. 2010;12:304-12. The study referenced here describes a content analysis of the educational materials on the websites of 29 health-related direct-to-consumer testing company websites and finds wide variability in the quality and usability of the information made available to consumers.

26. 23andMe, Inc. 11/22/13. 2013. http://www.fda.gov/ICECI/ EnforcementActions/WarningLetters/2013/ucm376296.htm. Accessed 15 Jan 2014.

27. Allain DC, Friedman S, Senter L. Consumer awareness and attitudes about insurance discrimination post enactment of the Genetic Information Nondiscrimination Act. Fam Cancer. 2012;11:637-44.

28. Laedtke AL, O'Neill SM, Rubinstein WS, Vogel KJ. Family physicians' awareness and knowledge of the Genetic Information Non-Discrimination Act (GINA). J Genet Couns. 2012; 21:345-52.

29. Mills Shaw KR, Van Horne K, Zhang H, Boughman J. Essay contest reveals misconceptions of high school students in genetics content. Genetics. 2008;178:1157-68.

30. The Nation's Report Card: science 2000. 2003. http://nces.ed. gov/pubsearch/pubsinfo.asp?Pubid=2003453. Accessed 14 Jan 2014.

31. Dougherty MJ. Closing the gap: inverting the genetics curriculum to ensure an informed public. Am J Hum Genet. 2009;85:6-12.

32. Redfield RJ. "Why do we have to learn this stuff?"- - a new genetics for 21st century students. PLoS Biol. 2012;10:e1001356.

33. Lyons KC. 2012 National Survey of Science and Mathematics Education: status of high school biology. Chapel Hill: Horizon Research Inc.; 2013.

34. Nelkin D, Lindee MS. The DNA mystique: the gene as a cultural icon. New York: Freeman; 1995.

35. Condit CM. How the public understands genetics: non-deterministic and non-discriminatory interpretations of the "blueprint" metaphor. Public Underst Sci. 1999;8:169-80.

36. Lynch J, Parrott A, Hopkin RJ, Myers M. Media coverage of direct-to-consumer genetic testing. J Genet Couns. 2011;20: 486-94.

37. Condit CM, Ofulue N, Sheedy KM. Determinism and massmedia portrayals of genetics. Am J Hum Genet. 1998;62:979-84.

38. Conrad P. Genetic optimism: framing genes and mental illness in the news. Cult Med Psychiatry. 2001;25:225-47.

39. Hyde J. News coverage of genetic cloning when science journalism becomes future-oriented speculation. J Commun Inq. 2006;30:229-50.

40. Machado H, Santos F. Popular press and forensic genetics in Portugal: expectations and disappointments regarding two cases of missing children. Public Underst Sci. 2011;20:303-18.

41. Kamenova K, Reshef A, Caulfield T. Angelina Jolie/'s faulty gene: newspaper coverage of a celebrity/'s preventive bilateral mastectomy in Canada, the United States, and the United Kingdom. Genet Med. 2013. http://www.nature.com/gim/journal/ vaop/ncurrent/full/gim2013199a.html. Accessed 30 Dec 2013.

42. Borzekowski DLG, Guan Y, Smith KC, Erby LH, Roter DL. The Angelina effect: immediate reach, grasp, and impact of going 
public. Genet Med. 2013. http://www.nature.com/gim/journal/ vaop/ncurrent/full/gim2013181a.html. Accessed 30 Dec 2013.

43. •• Brechman JM, Lee C, Cappella, Joseph N. Distorting Genetic Research About Cancer: From Bench Science to Press Release to Published News. J Commun. 2011;61:496-513. This study evaluated the accuracy and fairness of claims made in press releases and print media as compared with the original scholarly articles from which those claims derived. Its findings suggest some best practices for scientists, press offices, and journalists.

44. Fox S, Duggan M. Health online 2013. Pew Research Center. 2013. http://www.pewinternet.org/Reports/2013/Health-online. aspx. Accessed Jan 2013.

45. Anselmo M, Lash K, Stieb E, Haver K. Cystic fibrosis on the Internet: a survey of site adherence to AMA guidelines. Pediatrics. 2004;114:100-3.

46. Eysenbach G, Powell J, Kuss O, Sa E. Empirical studies assessing the quality of health information for consumers on the world wide web: a systematic review. JAMA. 2002;287:2691-700.

47. Reichow BSA, Bruder MB. Quality comparison of websites related to developmental disabilities. Res Dev Disabil. 2013;34: 3077-83.

48. Vital decisions: a pew internet health report. Pew Research Center. 2002. http://www.pewinternet.org/ /media//Files/Reports/2002/ PIP_Vital_Decisions_May2002.pdf.pdf. Accessed May 2002.

49. Wathen CN, Burkell J. Believe it or not: factors influencing credibility on the web. J Am Soc Inf Sci Technol. 2002;53: $134-44$.

50. $\bullet$ Alliance G. Trust it or trash it? A tool to help evaluate and create genetics health information. 2010. http://www.ncbi.nlm. nih.gov/books/NBK115530/. Accessed 22 Jan 2014. This is a valuable tool for anyone involved in developing genetics education materials or evaluating existing information.

51. Christian S, Kieffer S, Leonard N. Medical genetics and patient use of the Internet. Clin Genet. 2001;60:232-6.

52. Gundersen T. "One wants to know what a chromosome is": the internet as a coping resource when adjusting to life parenting a child with a rare genetic disorder. Sociol Health Illn. 2011;33:81-95.

53. Skinner D, Schaffer R. Families and genetic diagnoses in the genomic and Internet age. Infants Young Child. 2006;19:16-24.

54. Case DO, Johnson JD, Andrews JE, Allard SL, Kelly KM. From two-step flow to the Internet: the changing array of sources for genetics information seeking. J Am Soc Inf Sci Technol. 2004;55:660-9.

55. Glynn A, Saya S, Halliday J. Use and non-use of genetic counseling after diagnosis of a birth defect. Am J Med Genet A. 2012;158A:559-66.

56. Van den Bree MBM, Miller G, Mansell E, Thapar A, Flinter F, Owen MJ. The internet is parents' main source of information about psychiatric manifestations of 22q11.2 deletion syndrome (22q11.2DS). Eur J Med Genet. 2013;56:439-41.

57. Guttmacher AE, Porteous ME, McInerney JD. Educating healthcare professionals about genetics and genomics. Nat Rev Genet. 2007;8:151-7.

58. Wittmann E, Beaton C, Lewis WG, Hopper AN, Zamawi F, Jackson C, et al. Comparison of patients' needs and doctors' perceptions of information requirements related to a diagnosis of oesophageal or gastric cancer. Eur J Cancer Care. 2011; 20:187-95. 